\title{
IMPLANTAÇÃO DE UM DISPOSITIVO A PROVA DE ERROS (POKA YOKE) EM UM ATELIER DE COSTURA
}

\author{
Andressa Hélen Gonçalves Ventura (UFCG) Andressa-sjt@ hotmail.com \\ Beatriz Silva dos Passos Oliveira (UFCG) beattrizoliveira@ hotmail.com \\ Eloisa Soares de Aquino (UFCG) eloisaaquino11@ @otmail.com \\ Naiara Silva Nascimento (UFCG) naiaranascimento03@gmail.com \\ Jefferson Teixeira de Souza (UFCG) jefferson97ufcg@gmail.com
}

\section{Resumo}

Este artigo discorre sobre a implantação de um Poka Yoke em um atelier de costura, visando interferir consideravelmente na execução da atividade, uma vez que o objetivo é de fato corrigir uma falha nas máquinas do atelier, agregando eficiência no trabalho do funcionário, e reduzindo ao máximo o custo referente ao erro. Influenciando na gestão da qualidade e na redução de custos indesejáveis. Apresenta a definição de Poka Yoke e suas principais características, além da definição também de qualidade e sua importância nas empresas, com essas descrições é possível realizar um planejamento, a fim de garantir o controle da qualidade. Por fim, aborda-se a questão da qualidade nas empresas, e a importância e simplicidade da implantação de um Poka Yoke para facilitar o bom funcionamento nas empresas e nos maquinários

Palavras-Chaves: Controle de produção, Poka Yoke, Desperdício.

\section{Introdução}

Atualmente as empresas procuram o máximo de eficiência no seu processo produtivo, uma alternativa é o Poka Yoke, que visa obter zero defeitos na produção e eliminar as inspeções de qualidade, facilitando o controle. O Poka Yoke possui quatro tipos principais, sendo eles, de prevenção, de detecção, de valor fixo e de etapas.

Tendo em vista que o estudo foi desenvolvido em um ateliê de costura, e voltado exclusivamente para os maquinários onde está concentrado a maior chance de erros, o Poka Yoke utilizado foi o de detecção, visto que tem como objetivo, advertir por meio de sinais visuais e/ou auditivos o surgimento do erro, informando aos operários sobre sua origem de modo que uma prévia análise de contenção seja realizada.

Portanto, o objetivo desse trabalho é analisar uma linha de produção, e fazer a aplicação de melhorias através do Poka Yoke, contextualizando o mesmo no controle da qualidade. 


\section{Fundamentação teórica}

\subsection{Qualidade}

Para Lobo (2020), o termo qualidade consiste na totalidade das características de uma entidade que lhe confere a capacidade de satisfazer necessidades explícitas e implícitas dos clientes. Lobo (2020) define entidade como uma indústria fabricante ou uma empresa de prestação de serviços, necessidades explícitas são as demandas especificadas em contrato e necessidades implícitas como a demanda que a empresa precisa satisfazer, embora não especificadas em contrato, para obter um diferencial competitivo.

Segundo Silva (2009, p. 11), qualidade deriva da palavra latina qualitate e "é sinónimo da procura contínua de melhoria em todas as vertentes, desde a política e estratégia da organização até aos indicadores financeiros mais relevantes, passando pelos níveis de satisfação de todos os stakeholders".

De acordo com Garvin (1988), ao conceito de qualidade são atribuídas oito dimensões semelhantes às medições físicas. Essas dimensões estão descritas no Quadro 1.

Quadro 1: Dimensões da Qualidade

\begin{tabular}{|c|c|}
\hline Performance & Características operacionais primárias do produto. \\
\hline Características & $\begin{array}{l}\text { Características secundárias que permitem diferenciar os } \\
\text { produtos. }\end{array}$ \\
\hline Fiabilidade & $\begin{array}{l}\text { Probabilidade de um produto funcionar mal ou avariar. Mais } \\
\text { adequada a bens duradouros do que a serviços ou produtos } \\
\text { consumiveis instantaneamente. }\end{array}$ \\
\hline Conformidade & $\begin{array}{l}\text { Grau de adesão do produto a padrões previamente } \\
\text { estabelecidos. Relacionada com os custos associados à má } \\
\text { qualidade (funções de perda de Taguchi). }\end{array}$ \\
\hline Durabilidade & Medida do tempo de vida útil do produto. \\
\hline Serviço & $\begin{array}{l}\text { Inclui a rapidez, a cortesia, a competência e a facilidade em } \\
\text { reparar o produto. }\end{array}$ \\
\hline Estética & $\begin{array}{l}\text { Medida baseada em opinião pessoal que se refere à estética ou } \\
\text { apelo sensorial do produto. }\end{array}$ \\
\hline Qualidade Percebida & $\begin{array}{l}\text { Refere-se a uma percepção subjetiva de qualidade associada à } \\
\text { marca do produto ou à reputação de um fornecedor. }\end{array}$ \\
\hline
\end{tabular}

Fonte: Adaptado de Ferreira, P. L. (1991). Definir e Medir a Qualidade de Cuidados de Saúde. Revista Crítica de Ciências Sociais, (33), pp. 95-96 


\subsection{Gestão da qualidade total}

A Gestão da Qualidade Total ou Total Quality Management (TQM) é um modelo de gestão que potência a criação da consciência de qualidade em todos os processos organizacionais. Tem como objetivos: garantir a satisfação do cliente, promover o trabalho em equipe buscando o envolvimento de toda a organização, buscar constantemente a solução de problemas e a diminuição de erros (LONGO, 1996, p. 10).

Segundo Marques (2005, p.36), a busca pela melhoria contínua materializa-se com a criação de um sistema de auto avaliação permanente, capaz de avaliar a ciclos curtos, as atividades, o seu desempenho e resultados, tendo em consideração a análise dos resultados que vêm sendo conseguidos, a verificação da eficácia das atividades e práticas associadas e a detecção de áreas e oportunidades de melhoria.

Um ponto fundamental da TQM é a liderança. Cabe ao líder o papel de se apresentar como diferenciador e facilitador de melhorias continuadas graças a apetência que o mesmo deve possuir para a comunicação, a mudança, a visão, o trabalho de equipe, a busca de resultados, a pró-atividade e a empatia (MARQUES, 2005, p.38).

\subsection{A norma ISO 9001:2008}

Para padronização dos processos produtivos as empresas buscam implementar em seus sistemas, melhorias relacionadas as ferramentas de gestão da qualidade. Para isto, devem ser analisadas algumas normas que abordam esses aspectos.

A International Organization for Standardization (ISO) é uma entidade não governamental fundada em 1947 em Genebra, na Suíça, que congrega os organismos de normalização de 164 países e é responsável pela elaboração e publicação de normas internacionais em diversos campos técnicos. Estas normas internacionais são aprovadas através de consenso global e ajudam a quebrar as barreiras ao comércio internacional, indicando especificações de produtos e serviços, bem como as melhores práticas para tornar a indústria mais eficiente e eficaz (INTERNATIONAL ORGANIZATION FOR STANDARDIZATION [ISO], n.d.).

A norma ISO 9001:2008 tem como texto a definição dos requisitos de um sistema de gestão de qualidade e se baseiam na aplicação de oito princípios da gestão da qualidade, sendo eles:

a) Focalização no cliente: “As organizações dependem dos seus clientes e, consequentemente, deverão compreender as suas necessidades, atuais e futuras, 
satisfazer os seus requisitos e esforçar-se por exceder as suas expectativas" (NP EN ISO 9000 2005, 2005, p.7);

b) Liderança: "Os líderes estabelecem unidade no propósito e na orientação da organização. Deverão criar e manter o ambiente interno que permita o pleno envolvimento das pessoas para se atingirem os objetivos da organização" (NP EN ISO 9000 2005, 2005, p. 7);

c) Envolvimento das pessoas: "As pessoas, a todos os níveis, são a essência da organização e o seu pleno envolvimento permite que as suas aptidões sejam utilizadas em benefício da organização" (NP EN ISO 9000 2005, 2005, p. 7);

d) Abordagem por processos: "Um resultado desejado é atingido de forma mais eficiente quando as atividades e recursos associados são geridos como um processo" (NP EN ISO 9000 2005, 2005, p. 7);

e) Abordagem sistémica para a gestão: "Identificar, compreender e gerir processos interrelacionados como um sistema contribui para que a organização atinja os seus objetivos com eficiência e eficácia” (NP EN ISO 9000 2005, 2005, p. 8);

f) Melhoria Contínua: "A melhoria contínua do desempenho global da organização deverá ser um objetivo permanente dessa organização” (NP EN ISO 9000 2005, 2005, p. 8);

g) Abordagem fatual para a tomada de decisão: “As decisões eficazes são baseadas na análise de dados e de informações" (NP EN ISO 9000 2005, 2005, p. 8);

h) Relações benéficas com os fornecedores: "Uma organização e os seus fornecedores são interdependentes e uma relação de benefício mútuo potência a aptidão de ambas as partes para criar valor" (NP EN ISO 9000 2005, 2005, p. 8).

\subsection{A filosofia zero quality control (zqc) e o conceito poka-yoke}

A filosofia Zero Quality Control, desenvolvido por Shingo (1986) nos anos sessenta faz uso do controlo automático para evitar interrupções na linha de produção necessárias para realizar a inspeção dos produtos. A automatização permite identificar anomalias e, imediatamente, aplicar a ação corretiva, ou seja, a função de controlo é incorporada no processamento, permitindo uma detecção imediata e correção dos problemas. Deste modo, evita-se o fabrico de produtos defeituosos (SHINGO, 1986). 
Shingo (1986) salienta que é possível conseguir os "zeros defeitos" aplicando as características a seguir:

- Reconhecimento de que os trabalhadores podem errar utilizando-se, por isso, dispositivos à prova de erro que efetuam a função de controlo durante a execução dos produtos;

- Utilização de inspeção na fonte, ou seja, as funções de controlo são aplicadas na etapa onde os defeitos são originados; desta forma, o controlo é aplicado na detecção de erros antes que eles se convertam em defeitos, eliminando-se os custos associados;

- Utilização de inspeção a 100\%, ou seja, todos os itens produzidos são inspecionados;

- Redução do tempo decorrido entre a detecção de uma anomalia e a aplicação da ação corretiva.

De acordo com Shingo (1986), para que ocorra o "zero defeitos", é necessário que essas características sejam aplicadas na seguinte proporção: inspeção na fonte $-60 \%$; inspeção a $100 \%$ - 30\%; ação imediata - 10\%

Tendo origem japonesa, a palavra Poka-Yoke significa "prevenção de defeitos". A mesma surgiu no contexto da filosofia ZQC, e foi desenvolvido e implementado por Shingo, em 1961, na Toyota Motor Corporation.

Podendo ser traduzido como um mecanismo à prova de falhas, o Poka-Yoke evita que um erro seja cometido constituindo um recurso que indica ao operador o modo adequado para realizar uma determinada operação, impedindo a execução errada de determinada operação.

Os sistemas Poka-Yoke podem também apenas sinalizar, através de apitos, buzinas e sinais luminosos, a ocorrência de erros, sem parar a linha de produção, mas indicando a necessidade de correção (SHINGO, 1986).

Shingo (1996) determina que as origens dos erros estão relacionadas com problemas técnicos de gestão ou humanos, e o mesmos classifica os erros dos operadores em três tipos:

- Erros inadvertidos: são erros não intencionais resultantes da falta de atenção e que acontecem de forma aleatória; são intrínsecos à limitação humana, logo, não são afetados pelo nível de motivação; podem ser minimizados através da redução da necessidade da atenção do operador, de melhorias nas condições de trabalho, 
designadamente, eliminação das fontes de distração, rotatividade de tarefas, períodos de descanso e finalmente através da utilização de dispositivos à prova de erros;

- Erros de natureza técnica: estão relacionados com a falta de conhecimento, formação ou capacidade técnica para executar a operação corretamente; as soluções para estes erros envolvem basicamente, formação, alterações tecnológicas e melhorias do processo;

- Erros intencionais: são erros que os operadores cometem de forma premeditada; normalmente resultam de problemas de relacionamento do operador com as chefias, com a empresa ou até mesmo com a sociedade; a solução para este tipo de erros é mais de natureza psicológica do que propriamente técnica.

\subsection{Classificações de Poka-Yoke}

Shingo (1988), classifica os sistemas Poka-Yokes de acordo com o objetivo e as técnicas utilizadas. Quando vinculados ao objetivo, referem-se à função de regulagem, e quando ligados as técnicas referem-se à função de detecção.

A classificação de Shingo (1988) divide a função de regulagem em método do controle e método da advertência. O método do controle é assim denominado, pois o Poka-Yoke detecta uma variabilidade não esperada no processo e interrompe a operação, com os objetivos de evitar a produção de defeitos em série e criar um senso de urgência para que a ação corretiva seja implementada. No método da advertência, o Poka-Yoke detecta a anormalidade, mas não interrompe o processo, apenas sinalizando a ocorrência através de sinais sonoros e/ou visuais. Shingo (1986) classifica os dispositivos Poka-Yoke de acordo com as técnicas e mecanismos utilizados, resultando as classes apresentadas na figura 1.

Figura 1: Classificação dos dispositivos Poka-Yoke

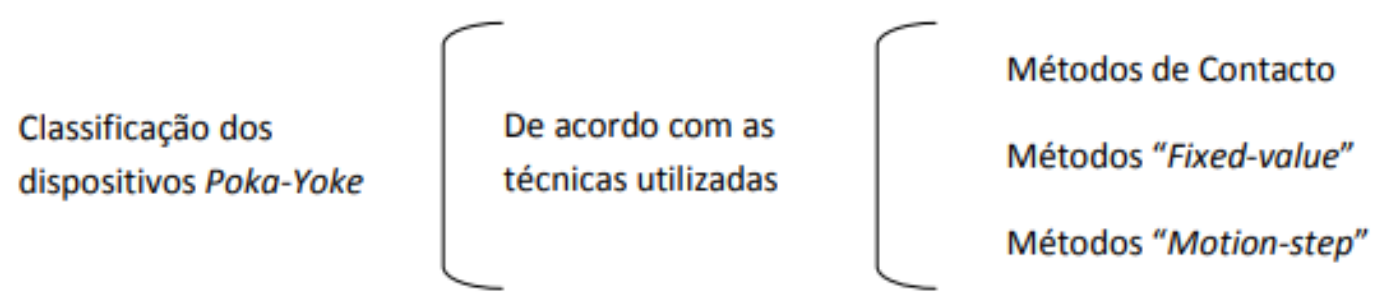

Fonte: Shingo (1986) 
Métodos de Contacto: utilizam dispositivos que detectam anomalias na forma ou dimensão do produto; pode haver ou não contato entre o dispositivo e o produto durante o processo de controlo; diferenças na tonalidade da pintura, é um caso que também pode ser detectado por este método, utilizando sensores que captam a luz refletida pela superfície do produto (SHINGO, 1986).

Métodos "Fixed-value": são utilizados para detectar anomalias em operações que incluem um número de movimentos/passos estabelecidos; o objetivo é garantir que nenhum desses movimentos/passos seja esquecido, através da contagem automática do número de movimentos realizados (SHINGO, 1986).

Métodos "Motion-step": são utilizados parar detectar anomalias em operações que incluem um padrão pré-estabelecido de movimentos/etapas; este método evita que o operador realize, por engano, uma etapa que não faz parte do procedimento preestabelecido (SHINGO, 1986).

Em seguida, Shingo (1986) descreve os mecanismos mais utilizados no desenvolvimento de sistemas Poka-Yoke de acordo com as funções desejadas.

Nos sistemas em que há contato entre os mecanismos e os produtos, utilizam-se frequentemente:

- Interruptores de limite e micro interruptores: confirmam a presença, posição de objetos e detectam ferramentas partidas, alguns incluem luzes para facilitar a inspecção de manutenção;

- Interruptores de toque: ativados por um toque ligeiro na antena; estes interruptores podem detectar com elevada sensibilidade a presença de objetos, posição e dimensões;

- Transformadores diferenciais: quando colocados em contato com o produto, geram-se flutuações nas linhas de força magnética permitindo detectar objetos com um alto grau de precisão;

- Electrónicos: são constituídos por um relógio comparador onde os valores limites, bem como a medição atual podem ser visíveis; os limites podem ser estabelecidos eletronicamente, permitindo que o dispositivo identifique a aceitabilidade das medições;

- Sensores de nível: detectam níveis de líquido sem o uso de flutuadores. 
Já em sistemas de detecção que não possuem o contato entre os mecanismos e os produtos, utilizam-se (SHINGO, 1986):

- Sensores de proximidade: estes sistemas respondem a mudanças nas linhas de força magnética causadas pela proximidade do objeto; só podem ser utilizados com materiais ferromagnéticos;

- Sensores fotoelétricos (de transmissão e de reflexão): nos de transmissão, o feixe transmitido entre dois sensores é interrompido pelo objeto a ser detectado; nos de reflexão, analisa-se o feixe luminoso refletido pelo objeto;

- Sensores de luz (de transmissão e de reflexão): estes sistemas de detecção fazem uso de feixes de eletros;

- Sensores de fibra: sensores que utilizam fibras ópticas;

- Sensores de área: a maioria dos sensores detectam apenas interrupções lineares, mas estes sensores podem detectar interrupções sobre uma área fixa;

- Sensores de posição: estes sensores detectam o posicionamento;

- Sensores de dimensão: estes sensores verificam se as dimensões estão corretas;

- Sensores de deslocamento: estes sensores que detectam deformações, espessuras e níveis de alturas;

- Sensores de passagem de metal: estes detectam a presença de metais misturados com outros materiais;

- Sensores de marcas coloridas: estes sensores detectam marcas de cor ou diferenças de cor;

- Sensores de vibração: estes podem detectar a passagem de produtos, a posição de soldaduras e fios partidos;

- Sensores de dupla-alimentação: estes sensores detectam dois produtos alimentados ao mesmo tempo;

- Sensores de posição de soldadura: detectam a mudança de composição metálica sem entrar em contato com o objeto; podem detectar soldaduras invisíveis superficialmente;

- Sensores com rosca: detectam erros de maquinação de furos roscados; 
- Sensores de elementos fluídos: estes dispositivos detectam mudanças nos fluxos de ar ocasionados pela colocação ou remoção de objetos (por exemplo detectam brocas partidas).

Porém, em sistemas que se medem pressões, temperaturas, correntes eléctricas, vibrações, número de ciclos, tempo e transmissões de informação, utilizam-se (SHINGO, 1986):

- Medidores de pressão que permitem detectar interrupções nos fluxos de óleo;

- Termómetros, termóstatos e termopares que podem ser usados para verificar a temperatura de moldes, componentes electrónicos, motores, entre outros tipos de medição e controlo de temperatura;

- "Meter relays" que são apropriados para controlar causas de defeitos através da detecção de flutuações da corrente eléctrica;

- Sensores de vibração que podem ser aplicados para detectar vibrações anormais de máquinas causadoras de defeitos;

- Contadores ou sensores de fibra óptica para detecção de contagens erradas;

- Temporizadores que podem ser utilizados para medir o tempo e durações;

- O som ou a luz podem ser utilizados para transmitir informações sobre anormalidades, o som capta mais a atenção dos operadores do que os sinais luminosos; o uso de luzes coloridas melhora a eficácia dos sinais luminosos.

\section{Metodologia}

O referente estudo, caracteriza-se como pesquisa pesquisa-ação, pois possibilita a intervenção dentro do estudo do problema, a fim de analisar, formular estratégias de ação para o problema, desenvolve-las e avaliar sua eficiência, possibilitando a ampliação da compreensão da situação e proceder os mesmos passos para novas situações do problema em questão (FOGAÇA).

O estudo desenvolveu-se a partir da necessidade do entendimento da aplicação do Poka Yoke, incentivado na disciplina de gestão da qualidade, com isso buscou-se um processo produtivo no qual seria analisado possíveis erros e tendo em vista a minimização destes erros seria aplicado o Poka Yoke.

A análise do processo produtivo, realizou-se em um atelier de costura onde a partir de visitas ao local, identificou-se a necessidade de aplicação do Poka Yoke nos maquinários de costura, 
no qual se apresentava erros humanos. Os erros mais frequentes eram de esquecimento das canilhas na máquina para rebobinação das linhas, ocasionando em perdas de matérias (linhas), por acionar a máquina com o dispositivo de rebobinação ativo.

A fim de prevenir esses erros introduziu-se um dispositivo de led a máquina, onde ao acionar a rebobinação das canilhas à luz de led acende informando ao operador que este dispositivo está em uso, com isso ao acionar a máquina este vai entender que a rebobinação está ativa eliminando o erro e consequentemente evitando a perda de matérias, sendo seu desenvolvimento e preparação exposta a seguir.

\subsection{Preparação do poka yoke}

O desenvolvimento do Poka Yoke de prevenção e detecção, consistiu na realização de um sistema simples, tanto para o desenvolvimento quanto para sua operação, porém funcional e que atendesse a necessidade do problema em questão.

Com isso aplicou-se um interruptor de toque, como mencionado no referencial teórico, para sua construção utilizamos: Led, fio de eletrônica, micro controlador (eesp8266), jumpers para ligações, cabo USB, botão (chave de ligar e desligar o dispositivo) e fita isolante. Como mostra nas imagens abaixo:

Imagem 1: Botão de acionamento do Poka Yoke

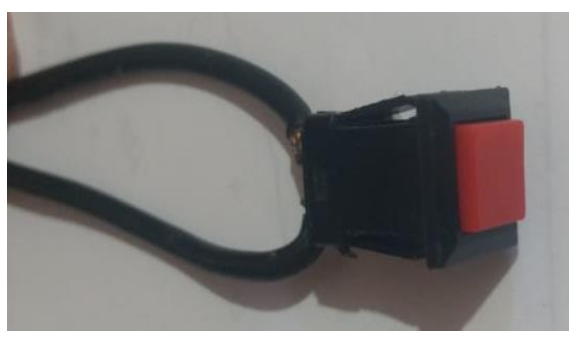

Fonte: Autoria Própria (2019)

Imagem 2: Led, microcontrolador e jumpers

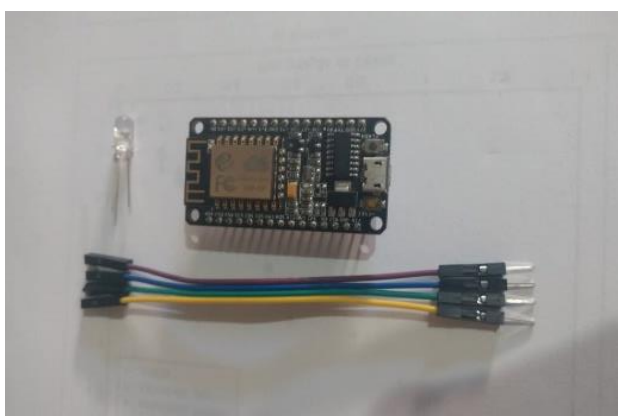

Fonte: Autoria Própria(2019) 
Imagem 3: Fita Isolante

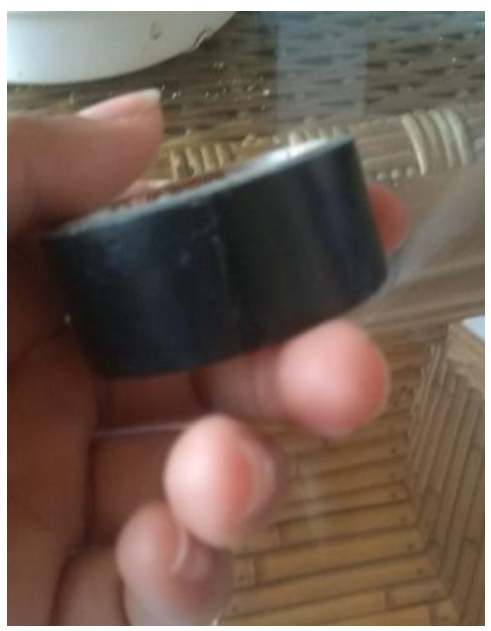

Fonte: Autoria Própria (2019)

A princípio foram interconectados todos os dispositivos com o fio, onde em uma extremidade se tem o botão (1), este conectou-se a placa micro controladora (2) e a uma das pontas do Led (3). O Led por sua vez, ligou-se ao micro controlador (4) e como mencionado acima, ao botão (3). E por fim, por esta conectado a ambos os dispositivos principais (Led e Botão) estabelece o controle entre ambos, para o microcontrolador (5) desenvolveu-se a linguagem de programação para o reconhecimento do botão (ligar e desligar o led) quando fosse acionado, este que além de controlar, alimenta o sistema, visto que sua entrada de alimentação permite conectividade com conectores atuais para receber energia e distribuir entre seus componentes. Com isso foi possível o desenvolvimento do Poka Yoke, como mostrado na figura 4, este atendendo as especificações do problema em questão.

Imagem 4: Montagem finalizada do Poka Yoke

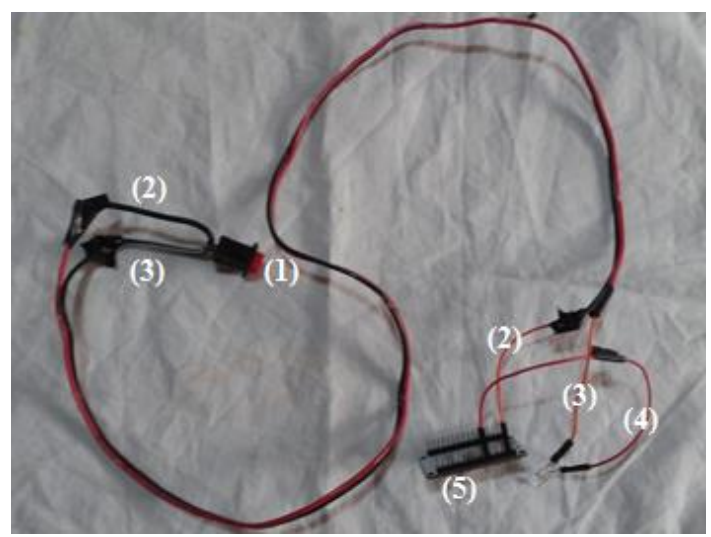

Fonte: Autoria Própria(2019) 


\section{Resultados}

Para solucionar o problema estudado presente na máquina de costura, desenvolve-se um Poka Yoke de detecção e prevenção, no qual este foi acoplado a máquina a fim de informar ao operador quando a alavanca de rebobinarão estiver ativa, a aplicação do Poka Yoke no maquinário será exposta no tópico abaixo.

\subsection{Aplicação do poka-yoke no maquinário}

Para a instalação do POKA-YOKE na máquina de costura se fez necessário o uso de fita isolante para fixar o sistema em sua estrutura. Primeiro acoplou-se o interruptor a alavanca da máquina, para que o mesmo seja pressionado simultaneamente ao toque do operador, quando o mesmo executa esse movimento para destravar o dispositivo de rebobinação como mostram as imagens 5 e 6 .

Imagem 5: Interruptor instalado na alavanca da máquina

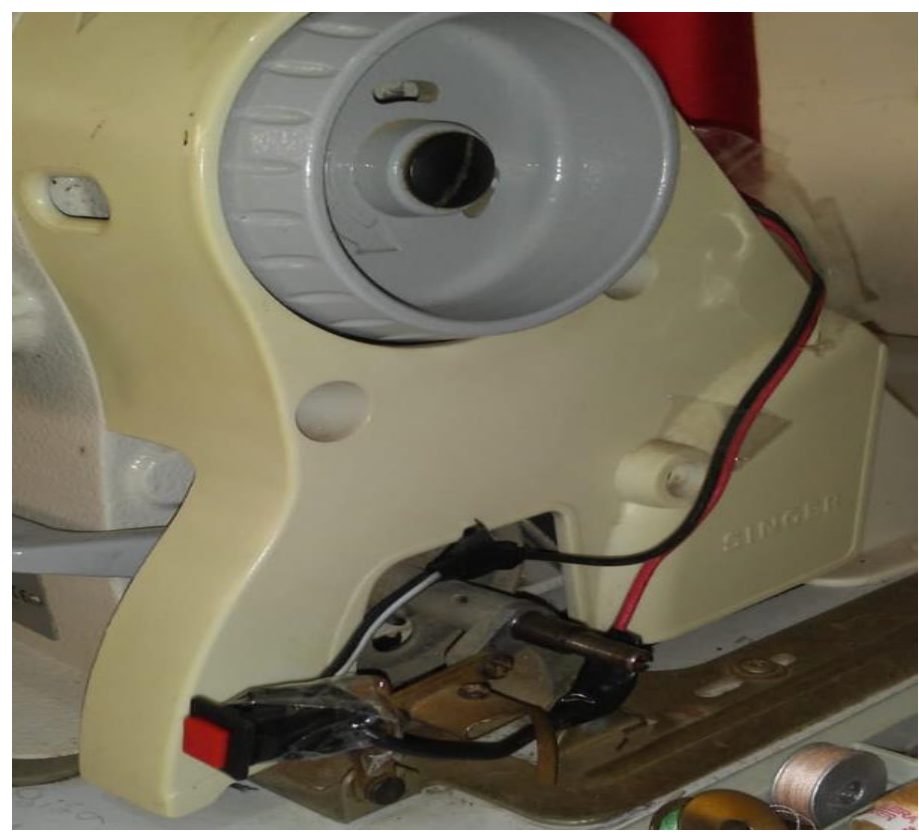

Fonte: Autoria própria (2019)

Imagem 6: Interruptor acoplado na máquina. 


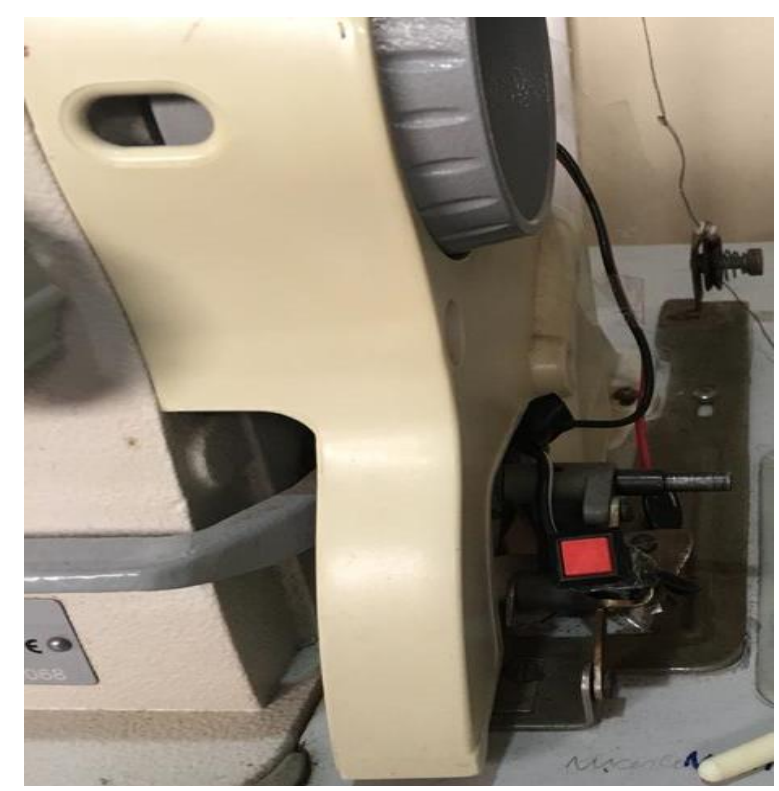

Fonte: Autoria própria (2019)

E por fim, posicionou-se o led na linha de visão do operador, para que assim, a luz que o led emite chame a atenção, fazendo com que o operador seja obrigado a pressionar o interruptor e consequentemente travar o dispositivo de rebobinação (Imagem 7).

Imagem 7: Led acoplado à máquina de costura.

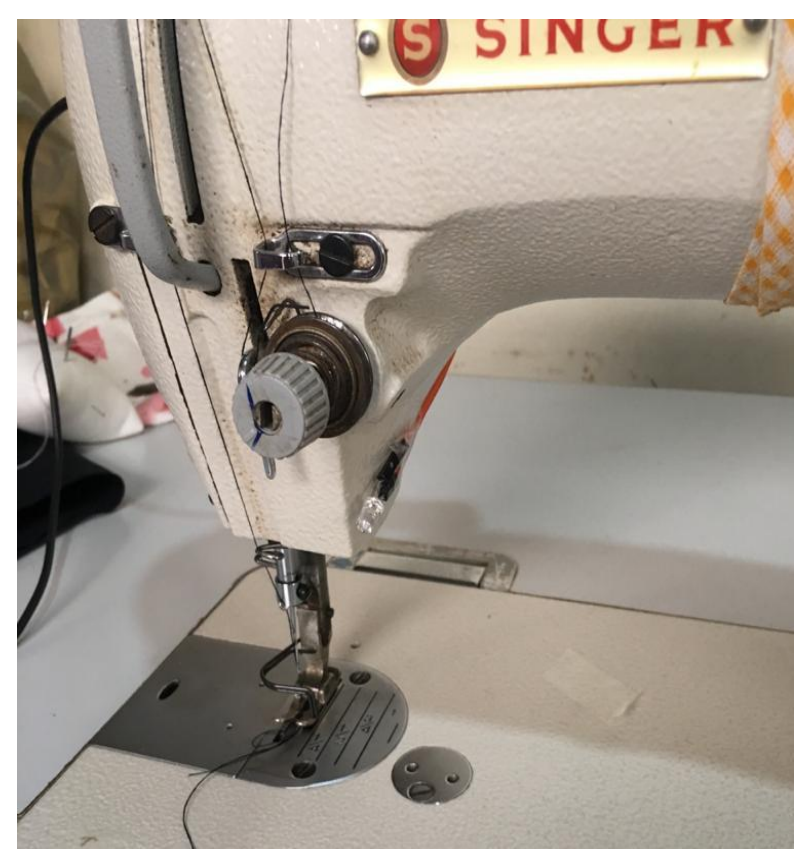

Fonte: Autoria própria (2019) 
Com isso, têm-se como resultado a minimização dos desperdícios de linha no processo produtivo. A imagem 8 mostra o sistema completo, já instalado na máquina.

\section{Imagem 8: Execução do POKA-YOKE.}

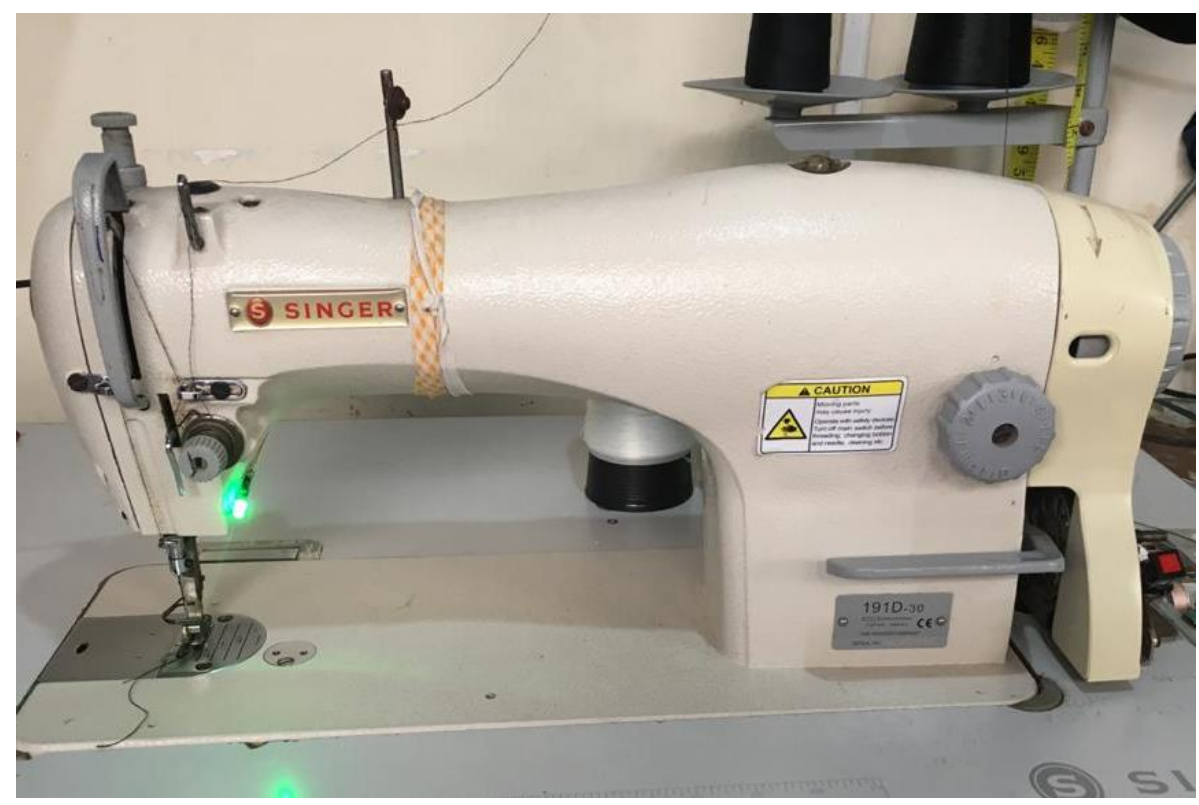

Fonte: Autoria própria (2019)

Após a instalação do Poka Yoke, a partir de observações notou-se uma redução dos desperdícios com linhas provenientes do sistema de rebobinação, visto que quando o operador retornava ao ponto de costura, este visualizava o led aceso e assimilava que a rebobinação estava ativa, levando-o a destravava o sistema de rebobinação da canilha, não avendo assim o desperdício de linha ao acionar a máquina para retornar suas atividades de costura, garantindo ao sistema uma melhor eficiência de sua operação, provenientes da redução dos desperdícios antes presentes.

\section{Considerações finais}

O presente trabalho permitiu demonstrar a aplicabilidade de sistemas à prova de erros no processo do ateliê. A implantação de um dispositivo de led possibilitou eliminar a causa do maior desperdício de linhas das máquinas, consequentemente reduziu custos, e melhorou a eficiência e qualidade do trabalho realizado.

A importância do Poka Yoke para processos produtivos e empresas, é a contribuição que o mesmo trás para a melhoria na efetuação das tarefas, reduzindo ou eliminando por completo erros que influenciam ativamente na atividade, tendo em visto que o mesmo é de fácil implantação e de custo acessível. 


\section{REFERÊNCIAS}

FOGAÇA, J. Pesquisa Ação. Brasil Escola. Disponivel em: <https://educador.brasilescola.uol.com.br/trabalhodocente/pesquisa-acao.htm>. Acesso em: 27 nov. 2019.

FERREIRA, P. L. (1991). Definir e Medir a Qualidade de Cuidados de Saúde. Revista Crítica de Ciências Sociais, (33), 93-112.

GARVIN, D. A. (1988). Managing Quality. New York: The Free Press.

International Organization for Standardization. (19 de Julho de 2013). Acesso em 27 de Novembro de 2019, disponível em ISO 9000 - Quality management.: http://www.iso.org/iso/home/standards/managementstandards/iso_9000.htm

LOBO, R. N. (2020). Gestão da qualidade. São Paulo: Érica

LONGO, R. M. (1996). Gestão da Qualidade: Evolução Histórica, Conceitos Básicos e Aplicação na Educação [Texto para discussão, No 397]. Brasília: IPEA.

MARQUES, A. S. (2005). Integração Normativa na Gestão da Qualidade (Dissertação de Mestrado, Universidade de Aveiro, Departamento de Economia, Gestão e Engenharia industrial, Aveiro, Portugal). Disponível:_http://hdl.handle.net/10773/4607" http://hdl.handle.net/10773/4607

NP EN ISO 90002005 (2005). Sistemas de Gestão da Qualidade. Fundamentos. Instituto Português da Qualidade.

SHINGO, S. 1986. Zero Quality Control: Source Inspection and the Poka-Yoke System. Massachusetts: Productivity Press.

SHINGO S. 1996. O sistema Toyota de produção, do ponto de vista da engenharia de produção. Porto Alegre: Artemed.

SHINGO, S. 1988. Zero quality control: source inspection and the poka-yoke system. Cambridge, MA: Productivity Press.

SILVA, M. Â. (2009). Desenvolvimento e implementação de um Sistema de Gestão da Qualidade (Dissertação de Mestrado, Universidade de Aveiro, Aveiro, Portugal). Disponível em: 〈http://hdl.handle.net/10773/1715">. 